\title{
Quality Improvement Project to Detect Use of Complementary and Alternative Medicine (CAM) in Patients at the Sepulveda VA Geriatric Medicine Clinic
}

\author{
Ecler Jaqua ${ }^{* 1,2}$, Nancy Weintraub ${ }^{2}$, Kristie Tu$^{2}$, Van Nguyen $^{1}$ and Jeffrey Cho ${ }^{1}$ \\ ${ }^{1}$ Department of Family Medicine, Loma Linda University, USA \\ ${ }^{2}$ Department of Geriatric Medicine, UCLA, USA
}

Submission: November 16, 2018; Published: January 08, 2019

*Corresponding author: Ecler Ercole Jaqua, Family Medicine, Loma Linda University, 1220 California Street, Suite 240, Redlands, CA 92374, USA

\begin{abstract}
Background/Objectives: The purpose of this project is to identify complementary and alternative medicine (CAM) use by patients seen at the VA Sepulveda ambulatory care center geriatric clinic. Failure to disclose CAM use to primary care providers may result in adverse interactions with prescribed medical treatments. We hope to increase detection of CAM use, and thus improve the safety of our patients by reducing potentially harmful polypharmacy.
\end{abstract}

Design: Survey study design.

Setting: VA Sepulveda ambulatory care center geriatric clinic in Los Angeles, CA.

Participants: 137 veterans, majority males, 65 years and older seeing the geriatric medicine team between October 2017 and February 2018.

Measurements: Geriatric clinic nurses provided patients and/or their caregivers a one-page questionnaire asking about to use of CAM while patients checked in to clinic. Once the questionnaire was collected, the geriatric fellow reviewed whether or not the questionnaire was appropriately documented in the electronic medical record.

Results: Out of 137 patients who were seen at the VA Sepulveda geriatric clinic, 115 patients use some form of CAM. 56.2\% of the CAM were over-the-counter medications, $34.2 \%$ alternative, herbal or natural supplements and $9.4 \%$ complementary therapy. $54 \%$ of the CAM were not documented in the EMR.

Conclusion: The vast majority of the patients at the VA Sepulveda geriatric clinic use CAM and more than 50\% were not documented, resulting in potential adverse interactions. Our goal is to encourage discussion about CAM in order to prevent medical complications arising from interactions between prescribed medications and CAM treatment, thereby improving patient safety.

Keywords: Complementary and alternative medicine; Older adults; Polypharmacy

\section{Introduction}

The purpose of this project is to identify complementary and alternative medicine (CAM) use by patients seen at the VA Sepulveda ambulatory care center geriatrics clinic.

About $50 \%$ of older adults use some form of CAM in the US and more than $40 \%$ of these patients do not disclose it to their primary care provider $[1,2]$. The use of CAM among older adults, and adults in general, is increasing each year. Failure to disclose CAM use to primary care providers may result in adverse interactions with prescribed medical treatments.

This subject is predominantly relevant in the older population because they use more medicines overall and complementary and alternative medicine compared with younger patients [2-4]. Among the many reasons patients decide to incorporate CAM into their conventional medical management is the dissatisfaction with the lack results of their current treatment along with many adverse effects. Other reasons include increased compatibility with their own cultural beliefs and values regarding their own health, as well as more autonomy regarding their well-being $[3,4]$.

Although the older population is a little more conscious about the health-related issues among CAM, they still need education and awareness about the side effects that come along with this type of treatment [2]. Herbal medicine, for example, is commonly used among our population and many patients are not aware about its potential harm $[3,5]$.

We hope to increase detection of CAM use and improve safety of patients by reducing potentially harmful polypharmacy and identify possible side effects. 


\section{Methods}

Two geriatric clinic nurses gave patients and/or caregivers the one-page questionnaire asking about use of CAM (Figure 1) before the clinic encounter. Once the questionnaire was collected, the geriatric fellow reviewed whether or not the answers were documented in the patients' charts. We used the Institute for Healthcare Improvement Model of Improvement, commonly known as the Plan-Do-Study-Act cycle and reviewed the results after 5 months of data collection starting in October 2017 and ending in February 2018. Descriptive statistics were used to analyze the data.

\begin{tabular}{|c|c|}
\hline Name:_ & al Security last 4\#: \\
\hline COMPLEMENTARY AND ALTER & IVE MEDICINE QUESTIONNAIRE \\
\hline 1. Are you taking any alternative, herb & natural supplements? \\
\hline [ ] Gingko Biloba & [ ] Marijuana/Cannabinoid \\
\hline [ ] Ginseng & [ ] Chondroitin/Glucosamine \\
\hline [ ] Garlic & [ ] Soy/Phytoestrogen \\
\hline [ ] Coconut Oil (Caprylidene) & [ ] Echinacea \\
\hline [ ] Fish Oil/Omega 3 & [ ] Valerian Root \\
\hline [ ] St. John's Wort & [ ] Cayenne Pepper \\
\hline [ ] Turmeric & [ ] Teas/Caffeine_ \\
\hline [ ] Saw Palmetto & [ ] Dietary Supplements _ \\
\hline [ ] SAM-e & [ ] Other \\
\hline 2. Are you taking any over the counter & ications? \\
\hline [ ] Tylenol products & $\begin{array}{l}\text { [ ] Laxatives/Fibers (ex. Psyllium, } \\
\text { Metamucil, Citrucel) }\end{array}$ \\
\hline $\begin{array}{l}\text { [ ] Anti-inflammatory (ex. Motrin, Advil, } \\
\text { Ibuprofen, Aleve, Naproxen) }\end{array}$ & [ ] Vitamins/Minerals \\
\hline [ ] Sleep aids (ex. Benadryl, Melatonin) & [ ] Other_ \\
\hline 3. Are you using any complementary $t$ & \\
\hline [ ] Acupuncture, Acupressure & [ ] Chiropractic manipulation \\
\hline [ ] Yoga, Tai Chi, Qigong & [ ] Meditation \\
\hline [ ] Massage & [ ] Homeopathy \\
\hline [ ] Cupping & [ ] Hypnosis \\
\hline [ ] Needling & [ ] Aromatherapy \\
\hline [ ] Deep Breathing/Relaxation exercises & [ ] Other_ \\
\hline
\end{tabular}

Figure 1: Multiple choice questionnaire that was used to ascertain the use of complementary and alternative medicine.

Results

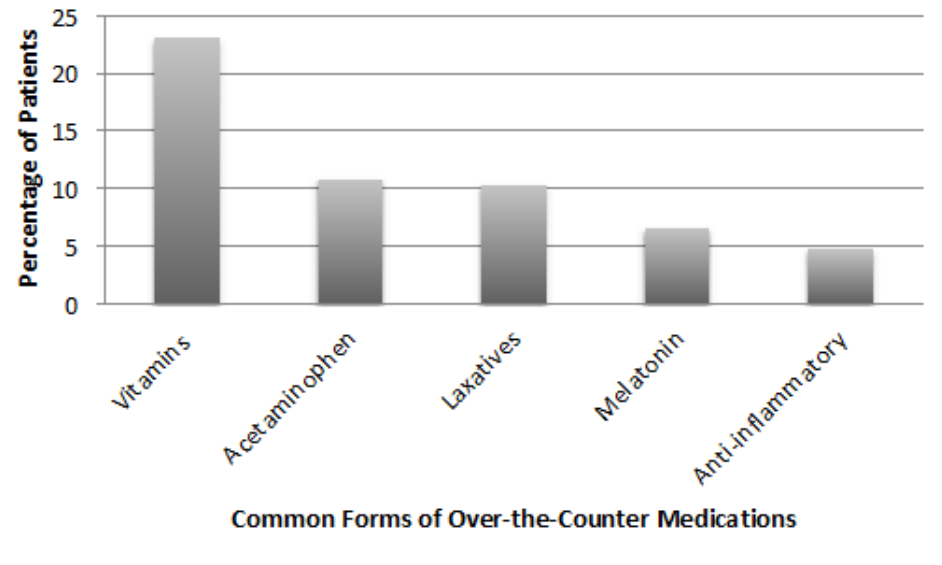

Figure 2: Percentage of patients using common forms of over-the-counter medications. 
At the VA Sepulveda geriatric clinic, 137 patients were evaluated, 126 of whom were male and 11 were female. Out of these 137 patients, 115 patients use some form of CAM. $56.2 \%$ of the CAM were over the counter medications; the most common being vitamins, acetaminophen and laxatives (Figure 2). $34.2 \%$ of the CAM were alternative, herbal or natural supplements, most commonly fish oil, tea, and turmeric (Figure 3). Relaxation, chiropractic services, and massage therapy comprised approximately $9.4 \%$ of CAM (Figure 4). The most common CAM used overall was vitamins, followed by acetaminophen, laxatives, fish oil, tea, and melatonin. Unfortunately, $54 \%$ of the CAM were not documented in the electronic medical record.

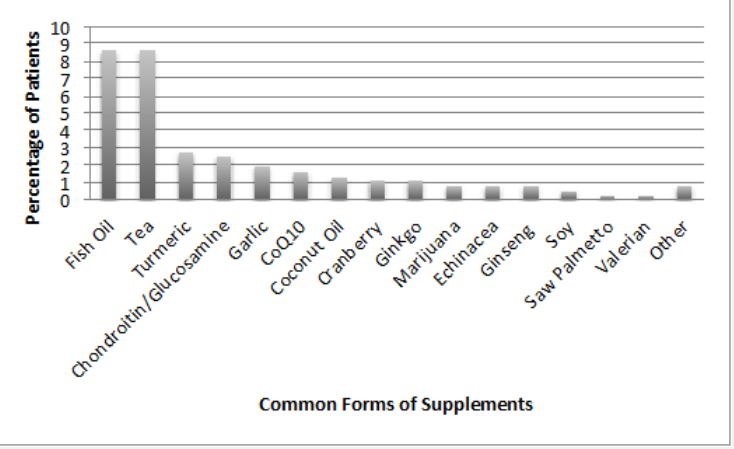

Figure 3: Percentage of patients using common forms of alternative, herbal, and/or natural supplements.

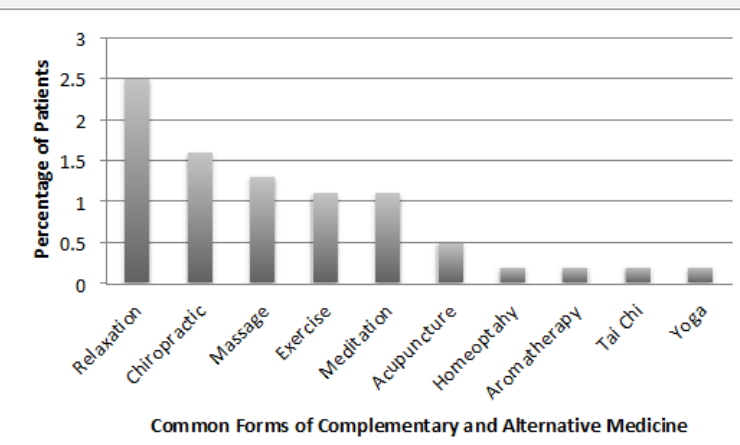

Figure 4: Percentage of patients using common forms of complementary alternative medicine.

\section{Discussion}

The vast majority of the patients at the VA Sepulveda geriatric clinic use CAM and more than 50\% were not documented in the electronic medical record or communicated to their primary care provider. This can lead to adverse outcomes and potential drug-drug interactions. In this study, we included over-thecounter medications as patients will often self-treat with these medications as alternative therapy, without consulting their physician, not knowing the potential harm of these therapies if not used appropriately.
In our quality improvement project, the most commonly used CAM were vitamins, $23.6 \%$. Unfortunately, this study was limited by not identifying the specific type of vitamins that patients were taking; it was assumed that the majority of these vitamins were daily multivitamins. Vitamins were followed by acetaminophen and laxatives in terms of the most commonly used over-thecounter CAM. This was closely followed by fish oil and teas.

According to the National Center for Complementary and Integrative Health (NIH), in 2007, the most popular products used among adults were fish oil/omega 3 , glucosamine, Echinacea, and flaxseed [6].

A national study from 1998 of over one thousand individuals reported that the most common CAM as chiropractic modalities, diet, exercise and movement, and relaxation [3]. The findings of this study were further confirmed by a study from 2005 that included over one thousand patients. Of these one thousand patients, $88 \%$ of respondents, over the age of 65 , used dietary supplements and chiropractic modalities most frequently [1].

In the United States, the use of CAM in the US is more prevalent than formerly reported $[2,4,7]$. It is most frequently used in patients that have been educated with a holistic emphasis and those who have had a transformational experience, most often with a poor health status $[3,8]$.

The goal of this study is to encourage discussion about CAM with the hope of preventing medical complications arising from interactions between prescribed medications and CAM treatment. This will improve patient safety. Further studies should be conducted to evaluate whether or not potential interactions between prescribed medications and CAM are statistically significant enough to warrant spending clinic time discussing CAM use with our geriatric patients.

\section{Acknowledgment}

All authors meet the criteria for authorship stated in the Uniform Requirements for Manuscripts Submitted to Biomedical Journals.

\section{References}

1. Ness J, Cirillo DJ, Weir DR, Nisly NL, Wallace RB (2005) Use of complementary medicine in older Americans: Results from the health and retirement study. Gerontologist 45(4): 516-524.

2. Welz AN, Emberger-Klein A, Menrad K (2018) Why people use herbal medicine: Insights from a focus-group study in German. BMC Complement Altern Med 18(1): 92.

3. Astin JA (1998) Why patient use alternative medicine: Results of a national study. JAMA 279(19): 1548-1553.

4. Eisenberg DM, Kessler RC, Foster C, Norlock FE, Calkins DR, et al. (1993) Unconventional medicine in the United States: Prevalence, costs, and patterns of use. N Engl J Med 328(4): 246-252.

5. MacLennan AH, Wilson DH, Taylor AW (1996) Prevalence and cost of alternative medicine in Australia. Lancet 347(9001): 569-573. 
6. Correction to Lancet Glob Health 2018; published online Sept 5. https://doi.org/10.1016/S2214-109X(18)30386-3. Lancet Glob Health. 6(11): e1162.

7. Sutherland LR, Verhoef MJ (1994) Why do patients seek a second opinion or alternative medicine. J Clin Gastroenterol 19(3): 194-197.
8. Vincent C, Furnham A (1996) Why do patients turn to complementary medicine? An empirical study. Br J Clin Psychol 35(Pt 1): 37-48.

\section{Your next submission with Juniper Publishers will reach you the below assets}

- Quality Editorial service

- Swift Peer Review

- Reprints availability

- E-prints Service

- Manuscript Podcast for convenient understanding

- Global attainment for your research

- Manuscript accessibility in different formats ( Pdf, E-pub, Full Text, Audio)

- Unceasing customer service

Track the below URL for one-step submission https://juniperpublishers.com/online-submission.php 